\title{
Psychometric properties of a clinical reasoning assessment rubric for nursing education
}

\author{
JuHee Lee', Chang Gi Park², Sung Hae Kim³ and Juyeon Bae ${ }^{4^{*}}$ (D)
}

\begin{abstract}
Background: Clinical reasoning is a vital competency for healthcare providers. In 2014, a clinical reasoning assessment rubric (CRAR) composed of analysis, heuristics, inference, information processing, logic, cognition and meta-cognition subdomains was developed for osteopathy students.

Methods: This study was conducted to verify the validity and reliability of the CRAR in nursing education. A total of 202 case vignette assessments completed by 68 students were used for exploratory factor analysis (EFA) and confirmatory factor analysis (CFA). The Cronbach's a coefficient of the CRAR was calculated.

Results: The content validity indices ranged from 0.57 to 1.0. The EFA resulted in three factors: assessment in nursing, nursing diagnosis and planning, and cognition/meta-cognition in nursing. The CFA supported a 3-factor model. The Cronbach's a coefficient of the CRAR was 0.94. This study confirmed the content validity, construct validity, and reliability of the CRAR. Therefore, the CRAR is a useful rubric for assessing clinical reasoning in nursing students.

Conclusions: The CRAR is a standardized rubric for assessing clinical reasoning in nurses. This scale will be useful for the development of educational programs for improving clinical reasoning in nursing education.
\end{abstract}

Keywords: Clinical reasoning, Rubric, Nursing education. Validity, Reliability, Psychometric evaluation

\section{Background}

Nurses use different reasoning processes depending on their knowledge and clinical experiences $[1,2]$. According to the Outcome-Present State Test (OPT) model, a theoretical framework for explaining the clinical reasoning process of nurses, accurate awareness of the patient's overall situation and context is essential in nurses' decision making and judgment [3]. Nurses use formal and informal thinking strategies such as deliberation and intuition through an individual's sense of salience, thereby, they use clinical reasoning skills to set priorities in

\footnotetext{
* Correspondence: porester@naver.com

${ }^{4}$ Department of Nursing, Yeoju Institute of Technology, Sejong-ro 338, Yeoju-si, Gyeonggi-do 12652, South Korea

Full list of author information is available at the end of the article
}

nursing care $[4,5]$. Novice nurses use deductive reasoning, which involves using information from the patient and caregiver to draw conclusions. It has been shown that novice nurses do not sufficiently consider salient information, tend to miss important cues, and often focus on the task rather than the patient [2]. In contrast, analytic processes can be used by experts, depending on the context and their knowledge of the situation. They collect data based on previous similar clinical experiences, recognize patient patterns, consider the patient context, and make a complex diagnosis based on these data $[1,2]$. Clinical experience with patients and educational level were found to be important factors in relation to nurses' clinical reasoning [6]. Therefore, nursing students need

C C The Author(s). 2021 Open Access This article is licensed under a Creative Commons Attribution 4.0 International License, which permits use, sharing, adaptation, distribution and reproduction in any medium or format, as long as you give appropriate credit to the original author(s) and the source, provide a link to the Creative Commons licence, and indicate if changes were made. The images or other third party material in this article are included in the article's Creative Commons licence, unless indicated otherwise in a credit line to the material. If material is not included in the article's Creative Commons licence and your intended use is not permitted by statutory regulation or exceeds the permitted use, you will need to obtain permission directly from the copyright holder. To view a copy of this licence, visit http://creativecommons.org/licenses/by/4.0/ The Creative Commons Public Domain Dedication waiver (http://creativecommons.org/publicdomain/zero/1.0/) applies to the data made available in this article, unless otherwise stated in a credit line to the data. 
more effort and education to acquire high-quality clinical reasoning [7].

Under the new learning paradigm that emerged during the industrial revolution, learning occurs through discontinuous semantic relationships and nonlinear thinking processes $[8,9]$. Learners connect the perspectives and ideas to which they are exposed lectures and clinical practicums. In this way, academic information is acquired. Clinical reasoning is affected by constructivism [2]. It is defined as a dynamic thinking process to integrate patient data, assess the significance of these data and choose alternative actions [10,11]. Levett-Jones and colleagues [2] developed the eight cyclic phases of the clinical reasoning model. Nurses used one or more clinical reasoning steps to reach clinical judgements. Clinical reasoning is a problem-solving process that occurs in the clinical context. Due to the uncertainties of patients' complex health problems, healthcare providers consider a large amount of data when solving patient problems. They need to make decisions using clinical reasoning [11]. Their clinical actions, or judgements, are part of the trajectory of patient outcomes.

The importance of clinical reasoning competency for nurses began to be more emphasized in the US in 2010 [12]. The American Nurses Association (ANA) recommended that clinical reasoning is a required core competency for integrating problem solving in clinical situations. It is a fundamental competency to develop in undergraduate nursing education programs [12]. In addition, having a graded prognostic assessment (GPA) was positively correlated with undergraduate students' clinical reasoning competency [13]. As a result, educational methods to improve clinical reasoning have been developed. Tyo and McCurry's integrative review [14] reported that simulation education, active learning strategies such as case studies, and collaborative learning are educational methods that can be used to enhance clinical reasoning. Nurses' clinical reasoning can ensure patient safety by allowing nurses to detect the worsening of symptoms [10]. Generally, clinical reasoning tools have been developed for health care professionals. In medical education, accurate diagnosis is an important aspect of clinical reasoning, while nursing education focuses on clinical reasoning in the nursing process. There is still a lack of sufficient measurement methods for evaluating clinical reasoning competency to support undergraduate nursing student's education. Liou and colleagues [15] developed a clinical reasoning measurement called the Nurses Clinical Reasoning Scale [NCRC]. The scale emphasizes the logical problemsolving process, which included nurses' data collection from patients, patients' recognition of problems, and nursing intervention evaluations. The clinical reasoning tool includes one factor and 15 items that are scored on a Likert scale. The Cronbach's $\alpha$ of the NCRC was found to be 0.9 , indicating its internal consistency. Clinical reasoning is a process used to identify scientific knowledge and evidence to be applied to patients. Nurses continually examine their level of understanding and their cognitive processes; if patient problems occur, nurses reflect and correct mistakes at the reasoning step. Metacognition, which is related to understanding and planning, serves to check and regulate nurses' cognitive states, and it is a key factor in the reasoning process [2]. The NCRC does not include an assessment of cognition and reflection to evaluate nurses' meta-cognition, which represents a limitation of the NCRC in measuring the core elements of clinical reasoning.

This study is therefore timely; it allows us to deepen our knowledge of the psychometric qualities of the tools. Orrock and colleagues [16] developed a clinical reasoning assessment rubric (CRAR) for osteopathy students based on Simmons' concept analysis [5] of clinical reasoning. Simmons [5] suggested attributes of clinical reasoning based on the nursing process. However, the construct validity of the CRAR has not been reported. This study was conducted to analyse the validity and reliability of a Korean version of the CRAR (K-CRAR) in nursing education.

\section{Methods}

This study was conducted to verify the psychometric properties of K-CRAR. In this study, we translated the CRAR into Korean and analysed its validity and reliability. We also developed three types of case vignettes to assess clinical reasoning competency using the CRAR. Our study partially used Kane's framework to assess the validation process of K-CRAR $[17,18]$. Kane's framework suggested a method of improving the validation rigor. Kane's framework consisted of domains named as scoring, generalisation, extrapolation, and implications. Extrapolation and implication domains used to examine the validation process. Extrapolation aimed at the measurement domain establishment. At this step, researchers searched the authoritative literature and consulted the experts. The implication domain helped the interpretation of the score using e.g., receiver operating characteristic (ROC). This study procedure as detailed in Fig. 1.

\section{Instrument}

The CRAR is composed of 14 items across 7 subdomains: analysis, heuristics, inference, information processing, logic, cognition, and meta-cognition. Each item of the rubric is scored from 1 to 5 points, with a total score ranging from 14 to 70 . A higher score indicates a higher level of clinical reasoning. The internal consistency test of the rubric reported a Cronbach's $\alpha=$ 0.944 [16]. 


\section{Step 1: The translation of CRAR}

- 3 bilingual researchers

- 1 bilingual nursing faculty

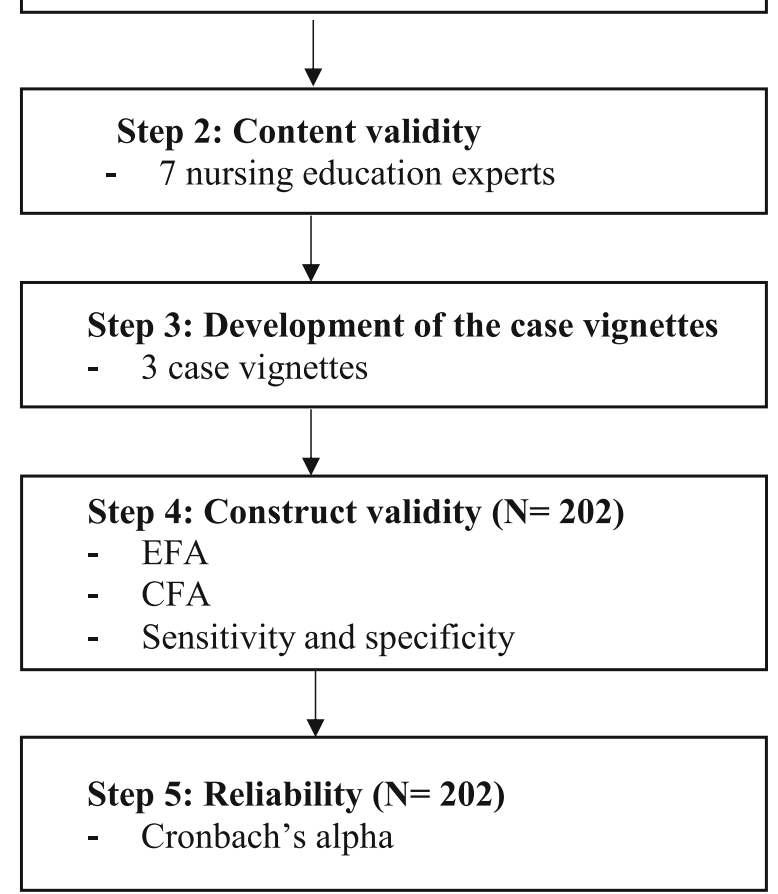

Fig. 1 The study process. Note: CRAR, Clinical Reasoning Assessment Rubric; EFA, exploratory factor analysis; CFA, confirmatory factor analysis

\section{Translation process}

The original CRAR was translated into Korean by the researchers after permission was obtained from the author [19]. The translation process was performed according to World Health Organization guidelines [20]. First, three bilingual researchers, including nursing professor, translated the text into Korean. Each researcher translated the CRAR independently. The translated K-CRAR was then revised by the researchers through a review of the items to consider the accuracy of the translation. During this process, the K-CRAR was translated into English for comparison to the original by bilingual nursing faculty who were experienced in psychometric validation. The preliminary K-CRAR draft was then completed.

\section{Content validity}

The content validity was examined by 7 nursing education experts who reviewed each rubric item via email in a one-round panel. The experts individually analysed the suitability of the content in terms of the language equivalence between the original and translated rubric. The experts were selected based on a list of faculties suggested by the Korean Accreditation Board of Nursing Education [21]. The experts verified the validity of the items by indicating the appropriateness of each item on a Likert scale from 1 ("not at all") to 4 ("very appropriate"). The experts commented about items that needs revision. The content validity index (CVI) was calculated, and items with $80 \%$ agreement were selected [22].

\section{Development of the case vignettes}

Case vignettes were developed based on nursing textbooks [23, 24]. We developed different types of case vignettes with different difficulty levels from easy to difficult. A pilot study was performed to estimate the 7 subdomains of the K-CRAR to ensure inter-rater agreement for the three cases. The researchers discussed points of disagreement until reaching a consensus. An example of a case vignette is shown in Additional file 1.

\section{Construct validity}

The construct validity was verified using exploratory factor analysis (EFA) and confirmatory factor analysis (CFA). The sensitivity and specificity were identified using a ROC curve to calculate the cut-off point.

\section{Reliability}

The internal consistency was examined using Cronbach's $\alpha$.

\section{Participants and procedure}

The required sample size was calculated using a method based on the root mean square error of an approximation method, which involved calculating the number of samples for the power in the factor analysis. For 70 degrees of freedom, a power of 0.8 , and an $\alpha$ of 0.05 , the required sample size was 200. Each participant completed three case vignettes, resulting in three samples per participant. Thus, at least 67 participants were needed, and a total sample size of 70 was used in case of dropouts. The inclusion criteria were 4th-year nursing students who had completed their clinical practicum courses and were able to understand the vignette cases and the purpose of the study. Participants were recruited from three universities in Korea from June to December 2018. A total of 68 4th-year nursing students participated in this study. One participant did not complete the assessment for two case vignettes. Therefore, a total of 202 case vignette assessments were included in the final analysis.

\section{Ethical considerations}

Ethical approval was provided by the Yonsei University College of Nursing Ethics Committee (2016-0028). Participants were recruited from three universities in Korea from June to December 2018. We obtained written 
informed consent from all participants prior to study enrolment.

\section{Statistical analysis}

The data were analysed using SPSS 23.0 and AMOS version 21.0. Descriptive statistics were used to analyse the participants' demographic characteristics. In this study, we performed validity and reliability tests. First, an item analysis was conducted. Second, the construct validity was identified using EFA and CFA. A principal component analysis and the varimax rotation method were used. The criteria of factor loadings were greater than 0.5 and a $p$ value less than 0.05 [25]. We used structural equation modelling for the CFA. The model fit criteria were as follows: chi-squared/degrees of freedom $\left(x^{2} / \mathrm{df}\right)$ $<3.0$, goodness-of-fit index $(\mathrm{GFI})>.90$, comparative fit index $(\mathrm{CFI})>.90$, normed fit index $(\mathrm{NFI})>.90$, TuckerLewis index $(\mathrm{TLI})>.90$, and standardized root mean residual $($ SRMR $)<.08$ [26, 27]. Third, the sensitivity and specificity were analysed using the area under the curve (AUC) on the ROC curve with cut-off point calculation. Hosmer and Lemeshow [28] reported a general rule for the interpretation of the AUC using the ROC curve as follows: $\mathrm{AUC}=0.5$ indicates no discrimination, $0.7 \leq$ AUC $<0.8$ represents acceptable discrimination, $0.8 \leq$ AUC $<0.9$ represents excellent discrimination, and AUC $\geq 0.9$ suggests outstanding discrimination. Lastly, the internal consistency and reliability were assessed using Cronbach's $\alpha$. This study consulted the statistician to corroborate the findings.

\section{Results}

\section{Content validity}

The CVI of the K-CRAR was 0.92 , ranging from 0.57 to 1.00 for each question. The experts commented on the meaning of "differential diagnosis" in the original tool. The preliminary K-CRAR did not include a differential diagnosis in the nursing process. However, the experts suggested that diagnostic approaches are an important skill for nurses. When patients have diverse and complex diseases, nurses should use multidimensional thinking strategies to analyse and distinguish patient information that can lead to decision making [12, 29]. Therefore, diagnostic identification was added to the rubric.

The experts suggested that the response option for item \#10 should be written as 'nursing intervention' rather than 'nursing diagnosis'. Based on the experts' comments, we rephrased item \#10 to include the term 'nursing intervention'.

\section{General characteristics and K-CRAR scores}

The general characteristics of the participants, including their K-CRAR scores, are shown in Table 1. The mean age of the nursing students was $22.53 \pm 1.4$ years. Of the 68 participants, 94.1\% were female. Aptitude and interest in nursing were the most frequent motivation factors for entering college $(n=29,42.6 \%)$. Most participants were satisfied with their major $(n=$ $44,64.7 \%)$ and clinical practicum $(n=40,58.8 \%)$. There was no significant difference in the clinical reasoning scores according to the participants' general characteristics. The scores ranged from 23 to 70 , and the mean score was $50.47 \pm 8.93$.

\section{Validity - exploratory factor analysis}

In Table 2, the EFA results are reported. The KaiserMeyer-Olkin coefficient was 0.84, and Bartlett's test of sphericity was significant at $p<0.001$, which was appropriate for factor analysis. All the factor loadings were significant $(p<0.05)$ and above 0.5 . Factors with eigenvalues greater than 1.0 were extracted. Overall, three factors explained $75.19 \%$ of the total variance in the 14 items. The eigenvalues of the three factors were 7.88 , 1.43, and 1.22, and these factors explained 56.26, 10.19, and $8.74 \%$ of the variance, respectively.

The scree plot showed a three-point threshold, and the plot dropped sharply after the first point. We renamed the factors according to their properties. The first factor was named "diagnosis and planning in nursing." It consisted of the inference, information processing, and logic subdomains of the original CRAR (items 5 to 10). The second factor was named "assessment in nursing," which was composed of the analysis and heuristics subdomains of the original CRAR (items 1 to 4 ). Lastly, the third factor was named "cognition and metacognition in nursing," which included the subdomain of the original CRAR (items 11 to 14 ).

\section{Validity - confirmatory factor analysis}

We analysed the model fit. The fit indices of the three-factor model were not adequate $\left(x^{2} / \mathrm{df}=5.619\right.$, $\mathrm{GFI}=.774, \quad \mathrm{CFI}=.858, \quad \mathrm{NFI}=.834, \quad \mathrm{TLI}=.826, \quad$ and SRMR =.091). We modified the model using the modification index, which showed covariance within the same factor as follows: errors 1 and 3, errors 4 and 5, and errors 7 and 9. The revised model fit indices, excluding the GFI, were adequate $\left(\mathrm{X}^{2} / \mathrm{df}=2.984\right.$, $\mathrm{GFI}=.859, \quad \mathrm{CFI}=.942, \quad \mathrm{NFI}=.915, \quad \mathrm{TLI}=.925, \quad$ and SRMR = .079) (Fig. 2).

\section{Sensitivity and specificity}

The sensitivity and specificity of the K-CRAR were tested using cumulative overall GPA scores. The GPA consisted of required and elective subjects, in addition to liberal arts points. We applied a cut-off point of a GPA grade of $\mathrm{A}^{+}$. The ROC curve and AUC are shown in Fig. 3. The AUC was 0.78 (95\% CI $0.62-0.95, p=0.004)$. This result showed that there was acceptable 
Table 1 Demographic characteristics of the study sample

\begin{tabular}{|c|c|c|c|c|}
\hline \multirow{2}{*}{ Age, mean } & \multirow{2}{*}{$\begin{array}{l}\text { Participants }(\boldsymbol{n}=68) \\
\mathbf{N}(\%) \text { or Mean (SD) } \\
22.53(1.4)\end{array}$} & \multicolumn{2}{|c|}{$\begin{array}{l}\text { K-CRAR Score }(n=202) \\
\text { N (\%) Mean (SD) }\end{array}$} & \multirow[t]{2}{*}{$t$ or $F(p)$} \\
\hline & & & $3.61(0.6)$ & \\
\hline \multicolumn{5}{|l|}{ Age (years) } \\
\hline$\leq 21$ & $13(19.1)$ & 39 (19.3) & $3.73(0.6)$ & 1.661 \\
\hline $22-23$ & $42(61.8)$ & $124(61.4)$ & $3.61(0.7)$ & (.193) \\
\hline$\geq 24$ & $13(19.1)$ & 39 (19.3) & $3.47(0.5)$ & \\
\hline \multicolumn{5}{|l|}{ Gender } \\
\hline Male & $4(5.9)$ & $12(16.8)$ & $3.52(0.7)$ & -.487 \\
\hline Female & $64(94.1)$ & $190(83.2)$ & $3.61(0.6)$ & $(.627)$ \\
\hline \multicolumn{5}{|l|}{ Admission Motivation } \\
\hline School grade & $5(7.4)$ & $15(7.4)$ & $3.51(0.6)$ & 2.247 \\
\hline Recommendation \& Advice & $14(20.6)$ & $42(20.8)$ & $3.74(0.7)$ & $(.065)$ \\
\hline Employment & $11(16.2)$ & $31(15.3)$ & $3.33(0.7)$ & \\
\hline Aptitude \& interest & $29(42.6)$ & $87(43.1)$ & $3.66(0.6)$ & \\
\hline Profession & $9(13.2)$ & $27(13.4)$ & $3.58(0.5)$ & \\
\hline \multicolumn{5}{|l|}{ Major Satisfaction } \\
\hline Very satisfied & $14(20.6)$ & $42(20.8)$ & $3.60(0.6)$ & 0.012 \\
\hline Satisfied & $44(64.7)$ & $132(65.3)$ & $3.61(0.6)$ & $(.988)$ \\
\hline Moderate & $10(14.7)$ & $28(13.9)$ & $3.59(0.7)$ & \\
\hline \multicolumn{5}{|l|}{ Clinical Practicum Satisfaction } \\
\hline Very satisfied & $6(8.8)$ & $18(8.9)$ & $3.85(0.5)$ & 1.742 \\
\hline Satisfied & $40(58.8)$ & $120(59.4)$ & $3.56(0.6)$ & $(.160)$ \\
\hline Moderate & $20(29.4)$ & $58(28.7)$ & $3.59(0.7)$ & \\
\hline Dissatisfied & $2(2.9)$ & $6(3.0)$ & $3.95(0.6)$ & \\
\hline \multicolumn{5}{|l|}{ Academic Achievement } \\
\hline High - Middle & $25(36.8)$ & $75(37.1)$ & $3.74(0.7)$ & 2.843 \\
\hline Middle & $24(35.3)$ & $70(34.7)$ & $3.55(0.6)$ & $(.061)$ \\
\hline Middle - Low & 19 (27.9) & $57(28.2)$ & $3.50(0.6)$ & \\
\hline
\end{tabular}

Abbreviations: K-CRAR Korean version of Clinical Reasoning Assessment Rubric, SD standard deviation

discrimination $(>0.05)$ and that the K-CRAR was suitable for screening [29]. To assess nursing students with high clinical reasoning, the cut-off level was set at 56 . The sensitivity was $66.7 \%$, and the specificity was $27.5 \%$.

\section{Reliability}

For the 14 items of the K-CRAR, the Cronbach's $\alpha$ coefficient was 0.94, indicating excellent internal consistency ( $N=68,202$ cases). The three subscales presented adequate internal consistency: 0.93 for diagnosis and planning, 0.92 for assessment, and 0.84 for cognition and meta-cognition.

\section{Discussion}

The importance of this study was that it suggested the standardized rubric to estimate clinical reasoning in nursing education. By providing the verified rubric, the study results will contribute to the development of educational programs for improving nurses' clinical reasoning. Originally, the CRAR was developed to measure the clinical reasoning of osteopathy students; however, the authors did not report the psychometric validation of the rubric. This study was conducted to evaluate the content validity, construct validity, and reliability of the K-CRAR to verify whether it can be used to measure clinical reasoning in undergraduate nursing students. This study provided a foundation for applying the clinical reasoning rubric in nursing.

All of the items of the K-CRAR except for one were confirmed suitable for measuring the clinical reasoning of nursing students [30]. The lowest CVI was for item \# 10 , which asked whether the learner could make a diagnosis and present a rationale for nursing intervention strategies. The content validity of the rubric indicates that it appropriately reflects the content or theme of measuring clinical reasoning. The accurate interpretation of terminology is important for verifying the 
Table 2 Exploratory factor analysis of K-CRAR according to component analysis ( $N=202)$

\begin{tabular}{|c|c|c|c|c|c|c|c|c|c|c|c|}
\hline \multirow{2}{*}{$\begin{array}{l}\text { K- } \\
\text { CRAR } \\
\text { item }\end{array}$} & \multirow[t]{2}{*}{ Mean } & & \multirow[t]{2}{*}{ SD } & \multirow{2}{*}{$\begin{array}{l}\text { Cronbach's } \\
\text { Alpha if } \\
\text { Item } \\
\text { Deleted }\end{array}$} & \multirow{2}{*}{$\begin{array}{l}\text { Corrected } \\
\text { Item-Total } \\
\text { Correlation }\end{array}$} & \multicolumn{3}{|l|}{ Factor Loading } & \multirow[t]{2}{*}{ Eigenvalue } & \multirow{2}{*}{$\begin{array}{l}\text { Variance } \\
\text { (\%) }\end{array}$} & \multirow{2}{*}{$\begin{array}{l}\text { Cumulative } \\
\text { variance } \\
\text { (\%) }\end{array}$} \\
\hline & & & & & & Component 1 & Component 2 & Component 3 & & & \\
\hline Item 9 & 3.64 & \pm & 0.84 & 0.94 & 0.70 & 0.88 & 0.19 & 0.17 & & & \\
\hline Item 8 & 3.68 & \pm & 0.85 & 0.93 & 0.77 & 0.86 & 0.28 & 0.22 & & & \\
\hline Item 10 & 3.59 & \pm & 0.85 & 0.94 & 0.69 & 0.85 & 0.18 & 0.20 & & & \\
\hline Item 7 & 3.45 & \pm & 0.87 & 0.93 & 0.79 & 0.65 & 0.32 & 0.47 & & & \\
\hline Item 6 & 3.58 & \pm & 0.84 & 0.93 & 0.73 & 0.64 & 0.31 & 0.37 & & & \\
\hline Item 5 & 3.58 & \pm & 0.85 & 0.93 & 0.76 & 0.56 & 0.55 & 0.25 & 7.88 & 56.26 & \\
\hline Item 2 & 3.23 & \pm & 0.82 & 0.94 & 0.66 & 0.18 & 0.86 & 0.19 & & & \\
\hline Item 3 & 3.61 & \pm & 0.92 & 0.93 & 0.77 & 0.29 & 0.82 & 0.29 & & & \\
\hline Item 1 & 3.38 & \pm & 0.87 & 0.94 & 0.69 & 0.20 & 0.81 & 0.28 & & & \\
\hline Item 4 & 3.51 & \pm & 0.95 & 0.93 & 0.75 & 0.32 & 0.79 & 0.27 & 1.43 & 10.19 & 66.46 \\
\hline Item 14 & 4.10 & \pm & 0.73 & 0.94 & 0.61 & 0.11 & 0.24 & 0.85 & & & \\
\hline Item 13 & 4.02 & \pm & 0.82 & 0.94 & 0.69 & 0.26 & 0.25 & 0.81 & & & \\
\hline Item 11 & 3.65 & \pm & 0.86 & 0.94 & 0.64 & 0.32 & 0.23 & 0.69 & & & \\
\hline Item 12 & 3.44 & \pm & 0.86 & 0.94 & 0.57 & 0.25 & 0.21 & 0.66 & 1.22 & 8.74 & 75.19 \\
\hline
\end{tabular}

Note: K-CRAR Korean version of Clinical Reasoning Assessment Rubric, SD standard deviation

content validity. The interpretation of terminology affects the rigor and completeness of an instrument [17]. In the case of item 10, the question and scoring criteria were phrased differently between the original and the translation; therefore, the item description was revised to improve the interpretation. In addition, nurses' evidence-based diagnostic competency was found to lead to positive outcomes for patients $[11,31]$. Therefore, the items evaluating accurate diagnosis, skills and strategies were maintained in the K-CRAR.

In case of measurements are translated into other languages, CFA is appropriate for construct validity [32]. Factor analysis was not performed for the CRAR during the development stage. Therefore, EFA and CFA were conducted to verify the construct validity of the rubric. Our study performed an EFA to identify the number of

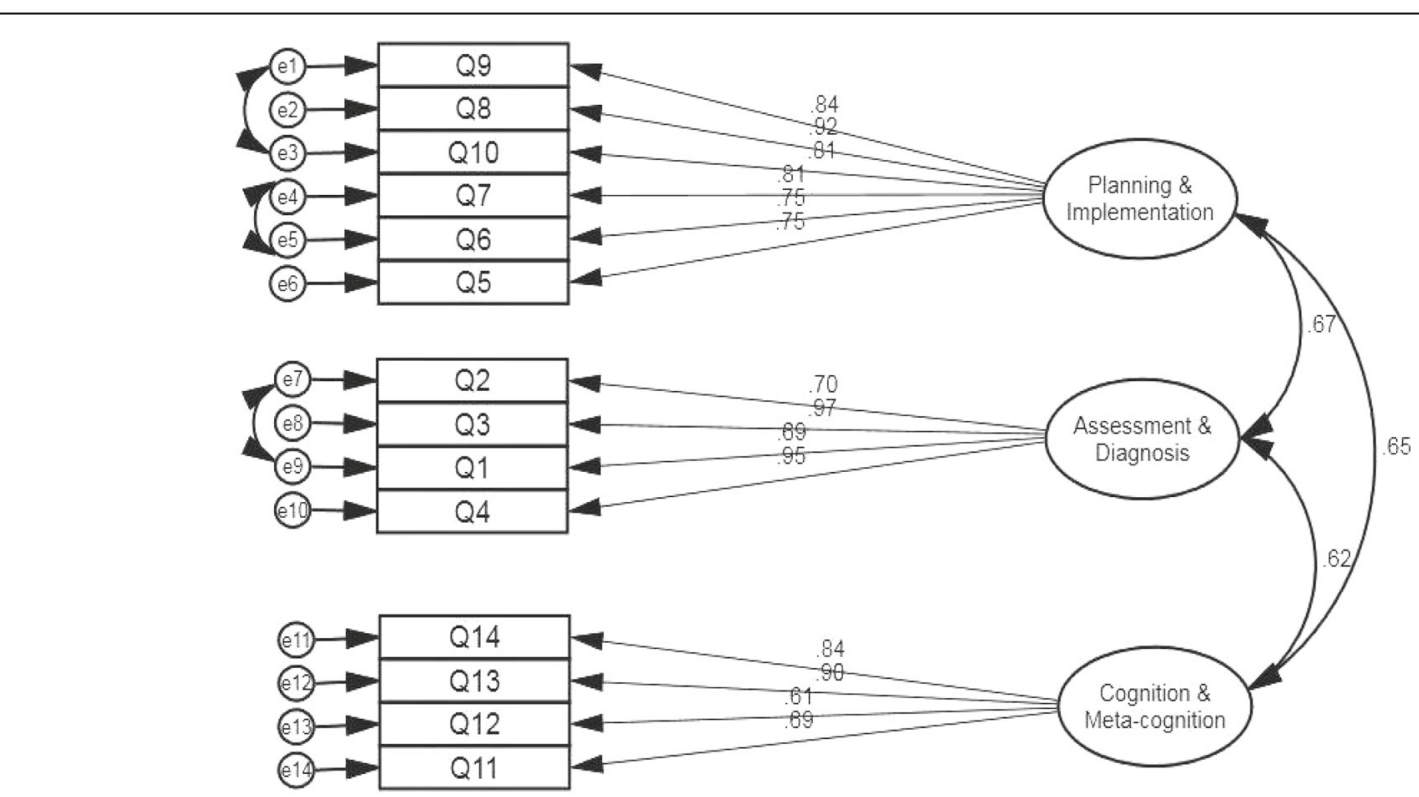

Fig. 2 Confirmatory factor analysis results of K-CRAR. Note: K-CRAR, Korean version of Clinical Reasoning Assessment Rubric 


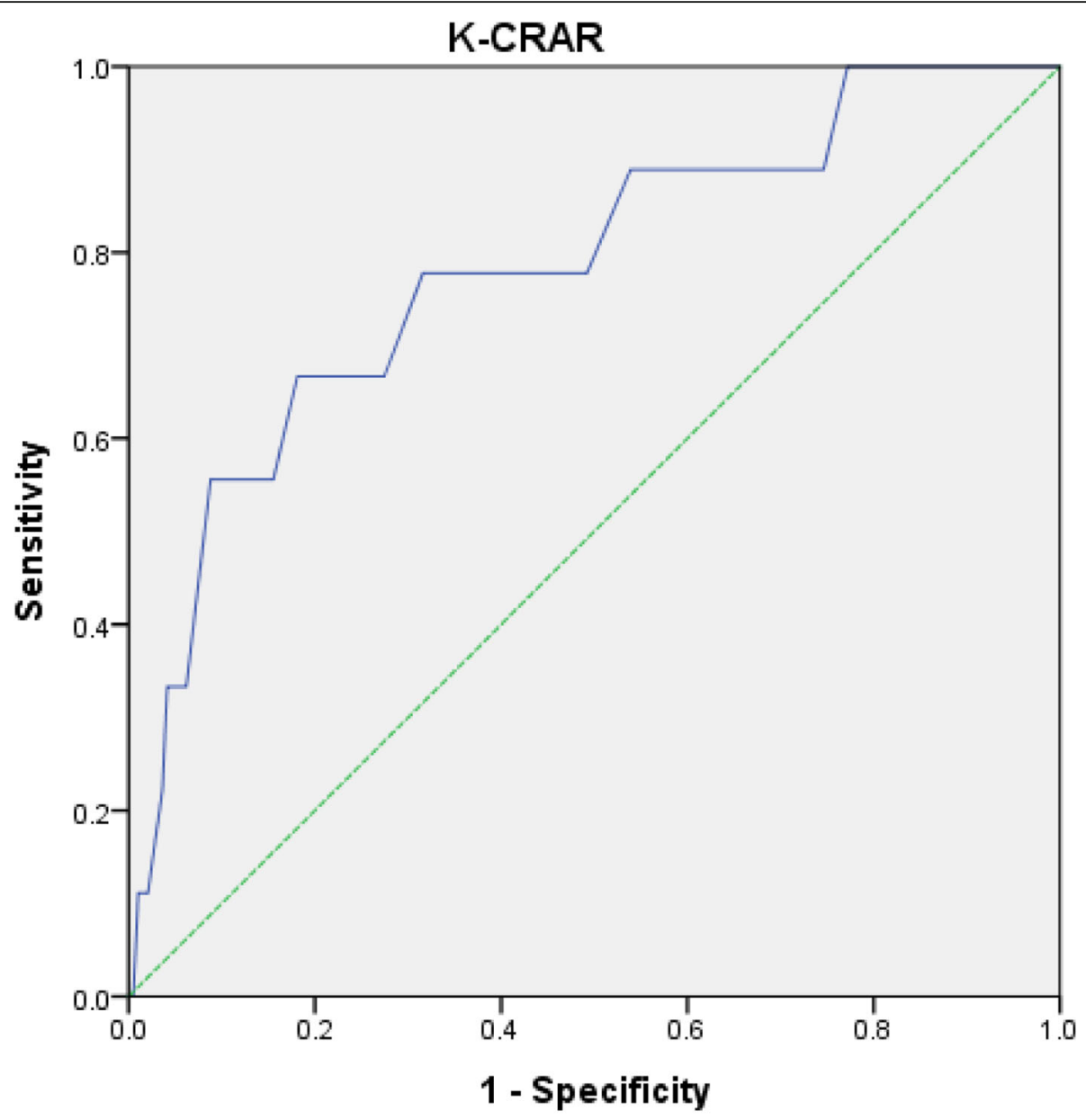

AUC $0.78(95 \% \mathrm{Cl} 0.62-0.95)$

Fig. 3 ROC curves and AUC for GPA grade score according to K-CRAR. Note: AUC, Area Under Curve; K-CRAR, Korean version of Clinical Reasoning Assessment Rubric; GPA, Graded Prognostic Assessment; ROC, Receiver Operating Characteristic

factors [33]. The original rubric consisted of seven subdomains with 1 to 3 items per factor. According to the EFA, the Korean version consisted of three subdomains. We renamed the factors according to aspects of the nursing process. The diagnosis and planning factor had the highest explanatory power, at $56.26 \%$. The nursing process is a systematic approach to nurses' problem solving [34]. This approach leads to problem identification in the overall context. Nurses' systematic thinking guides complex causality and accurate judgement [3]. This factor reflected the most effective, systematic aspect of clinical reasoning. The three factors of K-CRAR explained the $75.19 \%$ result. This is a similar result to previous psychometric testing of NCRC, a clinical reasoning scale. The NCRC's explanatory power was $50.66 \%$, and the Korean version of the NCRC was $61.63 \%[5,35]$. The K-CRAR satisfied Streiner's [36] criteria. Streiner proposed an explanatory power of at least 50 [36].
Overall, these findings indicate that the K-CRAR is an appropriate rubric for assessing clinical reasoning competency.

In this study, the CFA did not indicate a good fit of the model. We analysed the items connected to similar items the same attribute considering the covariance. The revised model fit indices, excluding the GFI, were adequate. The rubric could measure the clinical reasoning of nurses using all items and subscales. A modified three-factor measure was adopted for the final model. This model provided a possible explanation for why the theoretical model was not supported by the CFA. Further research is necessary to conduct repeated studies using CFA and EFA to provide an improved model.

The internal consistency of the test showed that the Cronbach's $\alpha$ for the overall measure was .94. The Cronbach's $\alpha$ coefficients of the subdomains ranged from 0.84 to 0.93 . The Cronbach's $\alpha$ of the original CRAR was 
94. Compared to other clinical reasoning tools, the NCRC Cronbach's $\alpha$ was .94, and the Korean version of the NCRC was .93 $[3,16]$. The rubric had high reliability among the participants of this study [37].

The AUC of the K-CRAR was 0.78. This rubric had moderate accuracy according to Greiner et al.'s [38] standard. Similarly, Suebnukarn \& Haddawy [39] developed a problem-based learning model for medical students that included clinical reasoning processes such as problem identification, problem analysis, hypothesis reporting and that had an AUC of 0.878, which was consistent with this study. The cut-off score is a significant indicator for evaluating scale accuracy in screening measurements. A cut-off value might be calculated to increase sensitivity [40]. It is appropriate to select cut-off values for both high sensitivity and specificity. The sensitivity of the K-CRAR was $66.7 \%$, and the specificity was $27.5 \%$, with a cut-off value of 56 . This result might have been due to the difficulty of the vignette cases. A factor potentially affecting the difficulty of the cases was the time elapsed since the participants had completed their clinical practicums. A previous study reported that students' acquired knowledge significantly decreased 8 weeks later after completing clinical practicums [41]. The study results may have been affected by recall bias. Despite the results, this study used diverse methods to examine the validity and reliability of the rubric. The KCRAR met the optimal cut-off point. This rubric is useful for evaluating the clinical reasoning of nursing students.

\section{Limitations}

The limitations of this study are as follows. First, the validity and generalizability of the results are limited because the sample comprised only undergraduate nursing students. Thus, a verification of the results with diverse samples (i.e., nurses or nurse practitioners) is suggested in the future. Second, the selected cut-off point was optimal. This was a multisite study. There were differences in the GPA level calculations by school. Thus, when this rubric is used, it is possible to change the cut-off point, and it is necessary to carefully interpret the results.

\section{Conclusions}

Clinical reasoning is a core competency for nurses. It is needed to emphasize fostering clinical reasoning in undergraduate nursing education. We verified a rubric for measuring the clinical reasoning of nursing students. The use of a standardized rubric enables the accurate and objective assessment of clinical reasoning. A standardized tool could be used to effectively measure the extent to which a researcher's intervention has made a difference.
It is important to develop educational programs to promote nurses' clinical reasoning so they can support people with health problems. This rubric provides an objective indicator of clinical reasoning development in education.

\section{Abbreviations}

CRAR: Clinical reasoning assessment rubric; EFA: Exploratory factor analysis; CFA: Confirmatory factor analysis; ANA: The American Nurses Association; NCRC: Nurses Clinical Reasoning Scale; CVI: Content validity index; ROC: Receiver operating characteristic; GFI: Goodness-of-fit index; CFI: Comparative fit index; NFI: Normed fit index; TLI: Tucker-Lewis index; SRMR: Standardized root mean residual; AUC: Area under the curve; GPA: Graded prognostic assessment

\section{Supplementary Information}

The online version contains supplementary material available at https://doi. org/10.1186/s12912-021-00695-z.

Additional file 1. Case vignette.

\section{Acknowledgements}

Not applicable.

\section{Authors' contributions}

\lrcorner designed this study and provided supervision and manuscript writing. CP supervised the study and analysed the data analysis. SK participated in the data collection, analysis and manuscript writing. JY collected data and performed analyses and manuscript writing. All the authors read and approved the final manuscript.

\section{Funding}

This work was supported by Mo-Im Kim Nursing Research Institute, Yonsei University College of Nursing (Grant number: 6-2016-0052).

\section{Availability of data and materials}

The authors confirm that all the relevant data are included in the article and its supplementary information files.

\section{Declarations}

Ethics approval and consent to participate

The study was approved by the Human Research Ethics Committee at the Nursing College of Yonsei University (approval number 2016-0028). All the students gave written informed consent to participate in the study. All the methods were performed in accordance with relevant guidelines and regulations.

\section{Consent for publication}

Not applicable.

\section{Competing interests}

The authors declare that they have no competing interests.

\section{Author details}

${ }^{1}$ Mo-Im Kim Nursing Research Institute, College of Nursing, Yonsei University, Yonsei-ro 50, Seodaemun-gu, Seoul 03722, South Korea. ${ }^{2}$ College of Nursing, University of Illinois at Chicago College of Nursing, 845 S. Damen Ave., MC 802, \#612, Chicago, IL 60612-7350, USA. ${ }^{3}$ Department of Nursing, Tongmyong University, Sinseon-ro 428, Nam-gu, Busan 48520, South Korea. ${ }^{4}$ Department of Nursing, Yeoju Institute of Technology, Sejong-ro 338 , Yeoju-si, Gyeonggi-do 12652, South Korea. 
Received: 29 January 2021 Accepted: 4 September 2021

Published online: 22 September 2021

\section{References}

1. Furze J, Kenyon LK, Jensen GM. Connecting classroom, clinic, and context: clinical reasoning strategies for clinical instructors and academic faculty. Pediatr Phys Ther. 2015;27(4):368-75. https://doi.org/10.1097/pep. 0000000000000185.

2. Levett-Jones T, Hoffman K, Dempsey J, Jeong SY, Noble D, Norton CA, et al. The 'five rights' of clinical reasoning: an educational model to enhance nursing students' ability to identify and manage clinically 'at risk' patients. Nurs Educ Today. 2010;30(6):515-20. https://doi.org/10.1016/j. nedt.2009.10.020.

3. Kuiper R, O'Donnell SM, Pesut DJ, Turrise SL. The essentials of clinical reasoning for nurses: using the outcome-present state test model for reflective practice: sigma Theta tau; 2017.

4. Benner $P$, Sutphen $M$, Leonard $V$, Day L. Educating nurses: A call for radical transformation, vol. 15: John Wiley \& Sons; 2010

5. Simmons B. Clinical reasoning: concept analysis. J Adv Nurs. 2010;66(5): 1151-8. https://doi.org/10.1111/j.1365-2648.2010.05262.x.

6. Kuiper RA, Pesut DJ. Promoting cognitive and metacognitive reflective reasoning skills in nursing practice: self-regulated learning theory. J Adv Nurs. 2004;45(4):381-91. https://doi.org/10.1046/j.1365-2648.2003.02921.x.

7. Vierula J, Haavisto E, Hupli M, Talman K. The assessment of learning skills in nursing student selection: a scoping review. Assess Eval High Educ. 2020; 45(4):496-512. https://doi.org/10.1080/02602938.2019.1666970.

8. Kim TS. A review of the report on future education in the era of the 4 th industrial revolution - focused on post-secondary and vocational education. J NRF. 2017;18(3):333-53. https://doi.org/10.15818/ihss.2017.18.3.333.

9. Seo HK. A basic study on the development of functional games for university lectures-focusing on clinical reasoning capabilities. J Korea Game Society. 2019;19(3):65-74. https://doi.org/10.7583/JKGS.2019.19.3.65.

10. Lapkin S, Fernandez R, Levett-Jones T, Bellchambers $H$. The effectiveness of using human patient simulation manikins in the teaching of clinical reasoning skills to undergraduate nursing students: a systematic review. JBI Libr Syst Rev. 2010;8(16):661-94. https://doi.org/10.11124/01938924-2010081 60-00001.

11. Leoni-Scheiber C, Mayer H, Muller-Staub M. Measuring the effects of guided clinical reasoning on the advanced nursing process quality, on nurses' knowledge and attitude: study protocol. Nurs Open. 2019;6(3):1269-80. https://doi.org/10.1002/nop2.299.

12. Alfaro-LeFevre R. Applying nursing process: the foundation for clinical reasoning: Lippincott Williams \& Wilkins; 2012.

13. Park WB, Kang SH, Lee YS, Myung SJ. Does Objective Structured Clinical Examinations Score Reflect the Clinical Reasoning Ability of Medical Students? Am J Med Sci. 2015;350(1):64-7. https://doi.org/10.1097/maj. 0000000000000420.

14. Tyo MB, McCurry MK. An Integrative Review of Clinical Reasoning Teaching Strategies and Outcome Evaluation in Nursing Education. Nurs Educ Perspect. 2019:40(1):11-7. https://doi.org/10.1097/01.Nep.0000000000000375.

15. Liou SR, Liu HC, Tsai HM, Tsai YH, Lin YC, Chang CH, et al. The development and psychometric testing of a theory-based instrument to evaluate nurses' perception of clinical reasoning competence. J Adv Nurs. 2016;72(3):707-17. https://doi.org/10.1111/jan.12831.

16. Orrock P, Grace S, Vaughan B, Coutts R. Developing a viva exam to assess clinical reasoning in pre-registration osteopathy students. BMC Med Educ. 2014;14(1):193. https://doi.org/10.1186/1472-6920-14-193.

17. Kane MT. Validating the interpretations and uses of test scores. J Educ Meas. 2013;50(1):1-73. https://doi.org/10.3389/fpsyg.2019.01131.

18. Cook DA, Brydges R, Ginsburg S, Hatala R. A contemporary approach to validity arguments: a practical guide to Kane's framework. Med Educ. 2015; 49(6):560-75. https://doi.org/10.1111/medu.12678.

19. Streiner DL, Norman G. R., \& Cairney, J. health measurement scales: a practical guide to their development and use. New York: NY: Oxford University Press; 2015.

20. World Health Organization (WHO). Process of translation and adaptation of instruments. 2016. http://www.who.int/substance_abuse/research_tools/tra nsla tion/en/. Retrived April, 2016.

21. Korean Accreditation Board of Nursing Education. Core competencies for nurses. 2012. http://www.kabon.or.kr/HyAdmin /upload/goodFile/ 120121127132143.pdf Retrieved April, 2016,
22. Lynn MR. Determination and quantification of content validity. Nurs Res 1986;35(6):382-5. https://doi.org/10.1097/00006199-198611000-00017.

23. Center HNT. Case studies in tuberculosis: nurse case management training tools bfor patient success; 2015.

24. Ignatavicius DD, Workman ML. Medical-Surgical Nursing-E-Book: PatientCentered Collaborative Care. edition t, editor. St. Louis, Missouri 63043: Elsevier Health Sciences.; 2015.

25. Lee CY. Advanced nurising statistics. Gyeonggi-do: Soomoonsa; 2016.

26. Kline RB. Principles and practice of structural equation modeling. 3rd ed: Guilford publications; 2015.

27. Schumacker RE, Lomax RG. A Beginner's guide to structural equation modeling. 3rd ed. New York: Routledge; 2010.

28. Hosmer DW, Lemeshow S, Sturdivant RX. Introduction to the logistic regression model. Applied Logistic Regression. 2000;2:1-30. https://doi.org/1 0.1002/0471722146.ch1.

29. Lee JH, Lee YJ, Bae JY, Seo MJ. Registered nurses' clinical reasoning skills and reasoning process: a think-aloud study. Nurse Educ Today. 2016;46:7580. https://doi.org/10.1016/j.nedt.2016.08.017.

30. Polit DF, Beck CT, Owen SV. Is the CVI an acceptable indicator of content 8validity? Appraisal and recommendations. Res Nurs Health. 2007;30(4):45967. https://doi.org/10.1002/nur.20199.

31. Perez Rivas FJ, Martin-Iglesias S. Pacheco del Cerro JL, Minguet arenas C, Garcia Lopez M, Beamud Lagos M. effectiveness of nursing process use in primary care. Int J Nurs Knowl. 2016;27(1):43-8. https://doi.org/10.1111/204 7-3095.12073.

32. Geldhof GJ, Preacher KJ, Zyphur MJ. Reliability estimation in a multilevel confirmatory factor analysis framework. Psychol Methods. 2014;19(1):72-91. https://doi.org/10.1037/a0032138.

33. DeVon HA, Block ME, Moyle-Wright P, Ernst DM, Hayden SJ, Lazzara DJ, et al. A psychometric toolbox for testing validity and reliability. J Nurs Scholarsh. 2007;39(2):155-64. https://doi.org/10.1111/j.1547-5069.2007.00161.x.

34. American Nurses Association. Nursing: Scope and standards of practice. 3rd ed. Silver Spring: MD: Author; 2015.

35. Joung J, Han JW. Validity and reliability of a Korean version of nurse clinical reasoning competence scale. J Korea Acad Industrial Cooperation Society. 2017;18(4):304-10. https://doi.org/10.5762/KAIS.2017.18.4.304.

36. Streiner DL. Figuring out factors: the use and misuse of factor analysis. Can J Psychiatr. 1994;39(3):135-40. https://doi.org/10.1177/070674379403900303.

37. Nunally JC, Bernstein IH. Psychometric theory. New York: McGraw-Hill; 1978.

38. Greiner M, Pfeiffer D, Smith RD. Principles and practical application of the receiver-operating characteristic analysis for diagnostic tests. Prev Vet Med. 2000;45(1-2):23-41. https://doi.org/10.1016/s0167-5877(00)00115-x.

39. Suebnukarn S, Haddawy P. Modeling individual and collaborative problemsolving in medical problem-based learning. User Model User-Adap Inter. 2006;16(3-4):211-48. https://doi.org/10.1007/s11257-006-9011-8.

40. Kwak JH, Kim JB, Choi JS, Kim HC, Jung SW, Lee EJ, et al. Study on standardization of Korean version of psychiatric diagnostic screening questionnaire: the optimal cutoff scores. J Korean Neuropsychiatr Assoc. 2012;51(2):77-84. https://doi.org/10.4306/jknpa.2012.51.2.77.

41. Kim HS, Choi EY. Continuity of BLS training effects in nursing students. J Korean Acad Soc Nurs Educ. 2012;18(1):102-10. https://doi.org/10.5977/jka sne.2012.18.1.102.

\section{Publisher's Note}

Springer Nature remains neutral with regard to jurisdictional claims in published maps and institutional affiliations.

Ready to submit your research? Choose BMC and benefit from:

- fast, convenient online submission

- thorough peer review by experienced researchers in your field

- rapid publication on acceptance

- support for research data, including large and complex data types

- gold Open Access which fosters wider collaboration and increased citations

- maximum visibility for your research: over $100 \mathrm{M}$ website views per year

At BMC, research is always in progress.

Learn more biomedcentral.com/submissions 